\title{
Examination of the eye-hand coordination related to computer mouse movement
}

\author{
Tibor Ujbányi, Attila Kővári, Gergely Sziládi and József Katona
}

\begin{abstract}
Eye-hand coordination means the ability to combine seeing and hand movement. Eye-hand coordination is a complex process consisting of a series of conscious actions. The fine motor skills of the hand were not born with us but learned. The development of eye-hand coordination has begun in infancy through various ball games, construction games and puzzle games. Co-ordinated work of eye and hand movement is the basis for many activities. The proper functioning of eye-hand coordination is necessary for many everyday activities such as writing, reading or driving. The joint work of the eyes and hands is vital for certain forms of movement (ball-catching, kicking). The eye plays an essential role in regulating fine movements. In this paper a general eye-hand coordination task is examined in relation to mouse cursor movement on computer screen. An eye-hand tracking system was used to observe the gaze and hand path during the mouse cursor movement and the acquired data were analyzed by statistical t-test.
\end{abstract}

Index Terms-statistical evaluation, paired t-test, eye-hand coordination, eye-tracking, hand tracking.

\section{INTRODUCTION}

$\mathrm{E}$ YE-HAND coordination is the ability to perform activities that require the simultaneous use of our hands and eyes as an activity that uses the information (visual-spatial perception) perceived by our eyes to control our hands. These activities are prerequisites for learning all kinds of activities, including writing and reading. [1]

The eye is used to transmit visual information. The hand is used to perform a specific task based on visual information received from the eye. Eye-hand coordination consists of a complex process, the decay of reflexes, and the practice of conscious action. [2] In our daily life, we use eye-hand coordination almost continuously. A skill that is essential in everyday life. Eye-hand coordination can be associated with motoric skills. [3]

Motoric skills are conditions for carrying out a motion action that can be traced back to the genetically determined components and components by learning. There are three types of motoric skills [4]:

- conditioning skills;

- coordination skills;

- joint mobility.

Motion coordination is the alignment of the motion phases and sequence of the partial movements. There are three types of basic motion coordination skills [5]:

- motion control skills;

- motion adaptive and motion adjuster skills;

- ability to learn the motion.

Correspondence: ujbanyit@uniduna.hu
The three basic skills can be further subdivided into abilities that result in motion order based on information that facilitates motion coordination. For example we use eye-hand coordination when writing. As we write the lines, our eyes send visual information to the brain about the position of the hand. With this information, the brain prepares instructions on how the hand should move in order to create appropriate lines of shapes, resulting in letters. There is a similar order when typing on a keyboard. The type of movement is different, but we still use visual information to tell the brain how to control our hands or if we need to fix an error [6]. Besides, we use eye-hand coordination while performing active activities (sports) that require motoric coordination.

We use eye-hand coordination during work, for example working on a material. We follow the shape of the workpiece with our eyes and we constantly transform it with our hands. It happens several times a day to open or close a door. Placing the key in the door lock and turning it in the right direction also requires eye-hand coordination. One of the most common examples is driving. We follow the road with our eyes while cornering and turn the steering wheel with our hands. [7]

The main aim of this paper to examine a general eye-hand coordination task in relation to mouse cursor movement on computer screen. The results can be used to compare the efficiency of computer mouse and gesture-based cursor position control by the perspective of eye-hand coordination. An eyehand tracking system was used to observe the gaze and hand path during the mouse cursor movement and the acquired data were analyzed by statistical t-test.

\section{METHODS THE DETECT OF EYE MOTION AND HAND TRACKING}

Many different techniques have been used in the past to track eye movement. Of these, there are essentially three techniques that we can find in researches. These techniques are:

- Electro-oculography (EOG),

- Video-oculography (VOG).

- Video-based infrared (IR) pupil-corneal reflection (PCR)

Electro-oculography (EOG) devices use electrodes placed around the eye to detect eye motion. The eye motion can be analyzed by the change of the electrode potentials. [8]

Video-oculography (VOG) is a video-based method of measuring the movements of eyes using a head-mounted mask that contains small cameras. The cameras send images to the computer for image processing. [9]

Video-based tracking contains a video camera that records 
the movements of the eyes and a computer that processes and analyses the gaze data like The Eye Tribe tracker (see below).

In order for a computer to perceive body language, it must follow the movement with a physical device. Many of the motion tracking systems have been developed over the years. Among the earliest was the DataGlove in 1980s. DataGlove is a multi-layered glove, equipped with multiple flex sensors, ultrasonic sensors to determine hand position and orientation. The metal strips in the sensor are measured for resistance to bending. One of the most popular gesture controllers among the new generation devices is the Kinect (Microsoft, 2016) based system which is developed for the latest generation of Xbox 360, Xbox One gaming consoles and desktop computers. The tool is now being developed by Microsoft. Its predecessor was the Xbox Live Vision system. The Leap Motion device uses cameras to detect hand and fingers position and there are some other open-source solutions using web cameras (see details under Test environment for analyzing eye and hand tracking data section). The Leap Motion Controller promises submillimeter accurate detection. In their article Weichert et al. the main focus of attention was on the evaluation of the accuracy and repeatability. It can be summarized that it was not possible to achieve the theoretical accuracy of $0.01 \mathrm{~mm}$ under real conditions but a high precision (an overall average accuracy of $0.7 \mathrm{~mm}$ ) with regard to gesture-based user interfaces. Comparable controllers in the same price range, e.g., the Microsoft Kinect, were not able to achieve this accuracy. [10]

Some researches were born in the past related to eye-hand coordination. Previous related researches have examined the relationship between eye-hand coordination in several aspects. Twardon et al used eye-hand coordination for an intuitive remote manipulation system that allows even non-expert users to operate a robot safely without prior experience. [11] Carrasco et al. in their article propose use of a visual sensor which allows the simultaneous analysis of hand and eye motions in order to recognize the reach-to-grasp movement to predict the grasping gesture. [12] Chiang et al in their study explore health benefits in somatosensory video games in case of older adults with wheelchairs based eye-hand coordination. [13] Renata et al has been shown the correlation between eye movement and reaction time under mental fatigue influence. [14] Johns et al examined the reaction time of the hand is influenced by the appearance of a visual signal. [15] Martin et al examined the features of head, eye and hand movement when driving. [16] Fischer et al. discovered that hand movement will be initiated when both eye and hand movement mental preparations are completed. [17] Dean et al. confirm the suggestion that the correlation between visual and reach reaction time exists. [18]

In our article, we conducted a comparative study between traditional cursor movement and gesture-based control while observing eye movement data. Based on our previous experience, when observing the mouse cursor movement with the help of Leap Motion, the test subject is more attentive and more closely observing the current position of the cursor than with the mouse cursor movement. This is probably due to the fact that moving the mouse cursor is a routine operation and therefore requires less continuous tracking of the cursor position during movement. We want to examine whether this assumption is true, whether the gaze is constantly following the mouse cursor movement, and whether it is constantly focusing on the mouse cursor movement using Leap Motion.

Two gaze mouse parameters can be examined with O.G.A.M.A. The first reports the number of fixations until the first mouse click (Gaze Mouse Path) and the second calculates the average distance between gaze and mouse path in pixels (Average Gaze Mouse Path Distance). The two related parameters were analyzed.

The purpose of the study is to examine the gaze mouse distance for two types of mouse cursor movement to provide a statistically detectable difference between the two control methods based on within-subjects design. For the correct application of the t-test, a number of conditions must be met. There should be no significant outliers. [19] The distribution of the differences in the dependent variable between the two related groups should be approximately normally distributed. We talk about the dependent t-test only requiring approximately normal data because it is quite "robust" to violations of normality, meaning that the assumption can be a little violated and still provide valid results. [20]

The eye movement sensor we use is located at the bottom of the screen. The position of both the screen and the eye movement sensor are fixed during the test and not move. We use a relatively large screen for better results (if the angle of the eye movement large across the screen, the relative error due to the angle of detection will be small). Touch screens are smaller and harder to fix. It is difficult to keep the screen-to-head distance required for testing, and the biggest difficulty is that in this case, when you touch the screen, the arm / hand can partially obscure the eye tracking image, so there will be insufficient data for evaluation. Therefore, touch screen testing was not included in the evaluation.

\section{A. Test environment for analyzing eye and hand tracking data}

The Eye Tribe portable eye tracker (Fig. 1.) was used to examine the gaze point of the test subjects. The tracker consists of two main components: a camera and a high-resolution infrared LED lamp. The camera tracks the user's eye movements and operates in $30 \mathrm{~Hz}$ and $60 \mathrm{~Hz}$ sample rate with an average accuracy of $0.5^{\circ}$. Its operational range varies between 45 and $75 \mathrm{~cm}$. [21-22] The Eye Tribe Tracker, contrary to its costefficiency, can be well-used in psychological researches. [23]

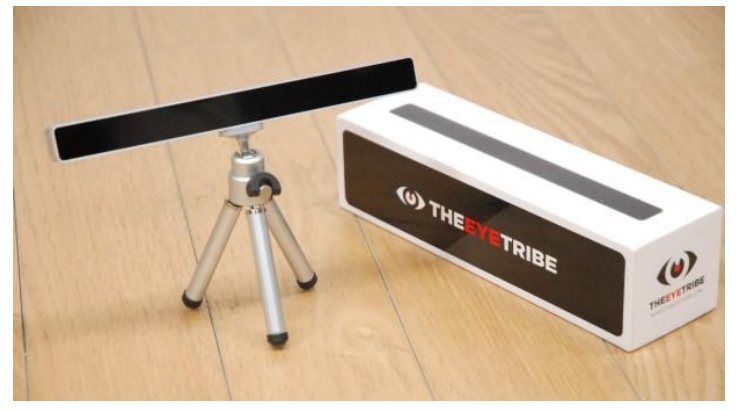

Fig. 1. The Eye Tribe tracker (source: https://i.ebayimg.com/images/g/YjwAAOSwNYFdGn1G/s-1300.jpg) 
Examination of the eye-hand coordination

related to computer mouse movement

The Leap Motion controller (Fig. 2.) is a small USB device that supports hand and finger motions as input without touching. The device using two monochromatic IR cameras and three infrared LEDs, the tool observes a roughly hemispherical area, to a distance of about 1 meter. The cameras generate almost 200 frames per second of reflected data. It is an optical hand tracking module that captures the movement of users' hands and fingers so they can interact naturally with digital content. Small, fast, and accurate, the Leap Motion Controller can be used for productivity applications with Windows computers, integrated into enterprise grade hardware solutions or displays, or attached to virtual/augmented reality headsets for AR/VR/XR prototyping, research, and development. The controller is capable of tracking hands within a $3 \mathrm{D}$ interactive zone that extends up to $60 \mathrm{~cm}$ (24") or more, extending from the device in a $120 \times 150^{\circ}$ field of view. [24] Leap Motion's software can discern 27 distinct hand elements, including bones and joints, and track them even when they are obscured by other parts of the hand. With a $120 \mathrm{~Hz}$ refresh rate and low-latency software, the time between motion and photon falls beneath the human perception threshold. [24]

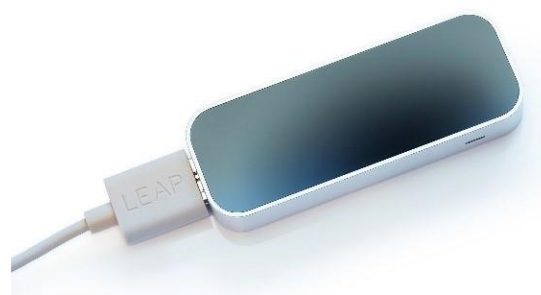

Fig. 2. The Leap Motion controller (source:

https://upload.wikimedia.org/wikipedia/commons/thumb/d/df/Leap_Motion_ Orion Controller Plugged.jpg/440px-

Leap_Motion_Orion_Controller_Plugged.jpg)

To analyze gaze point and mouse pointer location data the O.G.A.M.A software was used. It can co-operate with several eye-tracking systems like The Eye Tribe. [25] It uses databasedriven pre-processing and filtering of eye movements and mouse motion data. Data can be displayed and evaluated in several methods because the software contains 10 analyzer modules. [25]

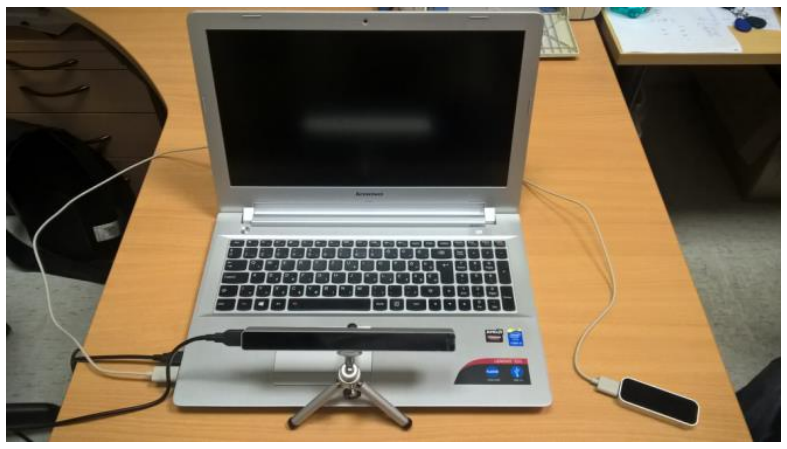

Fig. 3. The test environment with Eye Tribe Tracker and Leap Motion Controller

(source: own edited)
The test environment is based on a laptop with a higher than average Intel Core i5 processor. The Eye Tribe Tracker and Leap Motion Controller was connected via USB 3.0 ports. The test environment can be seen in Fig. 3.

\section{RESEARCH CONDITIONS}

The goal of the research is to examine the differences between the point of gaze and the location of the mouse pointer when the mouse pointer is controlled by traditional computer mouse and Leap Motion-based hand position detection. The test was performed using OGAMA with two similar test slides that can be seen in Fig. 4.

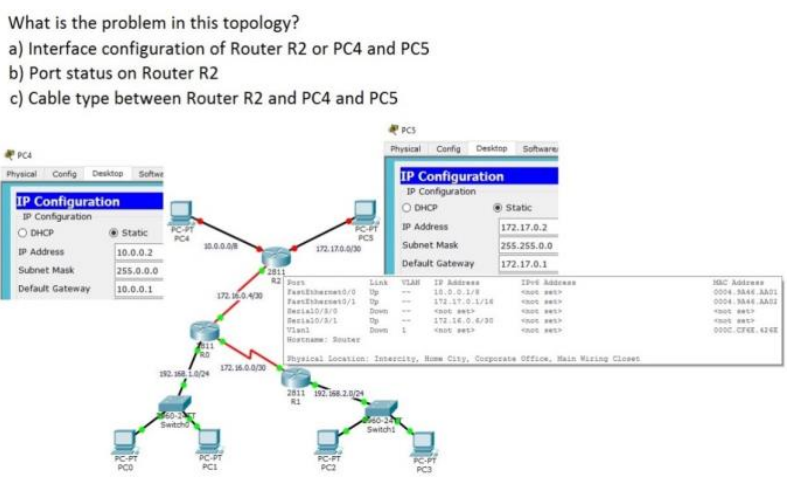

Fig. 4. Test slide (source: own edited)

The test subject had to select one of the answers moving the mouse pointer over the selected answer (Fig. 5.). The average gaze mouse path distance was analyzed in the case of the mentioned two mouse pointer control method. The goal of the research is to examine, whether there were differences in the average gaze mouse path distance.

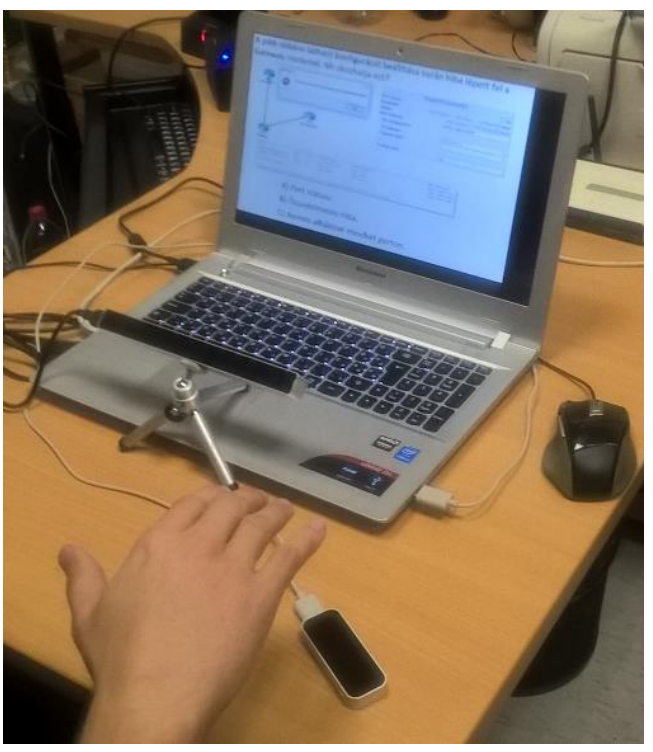

Fig. 5. Test subject while performing the task (source: own edited) 


\section{A. Test subjects}

32 graduated or school-leaver IT specialists participated in the research on voluntary basis. The participants of the study were primarily representing the younger generation, and there was also a foreign students among them. The gender distribution of the students: 28 males and 4 females. Their age all varied between 20 and 30 . The examination was performed in the afternoon in a closed room without disturbances.

\section{B. Methods}

Before the beginning of the test, testing subjects had to sit in front of the computer performing eye tracking. Then, using the OGAMA software, a calibration was performed first. If the calibration was successful, the test was performed. During the test, the test slide appeared on the display, where the correct answer could be selected by moving the mouse cursor by different control methods: first with a traditional computer mouse, second with Leap Motion hand motion control on two slightly different test page. The two test pages consist of similar questions the two tests were slightly different. The study was within-subject type and all subjects performed the task in the same order - firstly using a mouse, secondly using Leap Motion. The post-processing of the gaze point and mouse cursor data were performed following the tests.

The gaze point and mouse cursor data were evaluated using statistical analysis based on within-subjects design. The statistical evaluation of data was performed using the SPSS 25 software package. In the case of normal data distribution, Shapiro-Wilk (S-W) normality test was performed. Statistical evaluation of average gaze mouse path distance was performed using Paired Samples t-test, $\mathrm{p}<=0.05$ value was considered as significant.

\section{Main Results}

Using the Paired t-test analysis the means between two measures on the same continuous variable is compared. The dependent variable, average gaze mouse path distance is measured at the interval level. The independent variable consists of two categorical "matched pairs" according to mouse pointer motion control by computer mouse and hand controller.

\section{Outliers}

First the outlier, data point that does not fit the general trend of your data, is detected by plotting the differences on a graph and visually inspecting the graph for outlier points. Descriptive and Boxplot is used to identify outliers as extreme values. In the analysis a step of $1.5 \times$ Interquartile range (IQR) is used to detect extreme values. The Boxplot is shown in Fig. 6.

According to descriptives of differences the Mean=40.59, $\mathrm{IQR}=37.5$, Maximum=87 and Minimum=5 and figure of Boxplot there is no outliers.

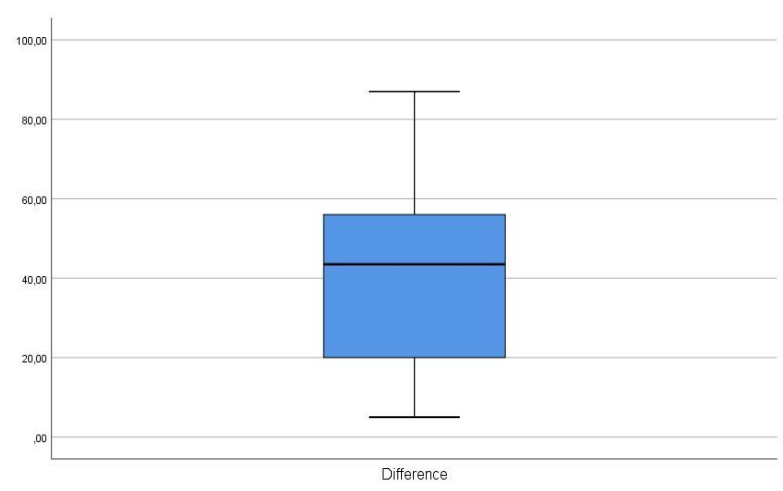

Fig. 6. Boxplot of differences between the two related groups on average gaze mouse path distance in pixels (source: own edited)

\section{E. Normality}

Differences of average gaze mouse path distances should be approximately normally distributed. The Paired Samples t-test requiring approximately normal data because it is quite "robust" to violations of normality.

The normality is analyzed using graphical Q-Q Plot and numerical Shapiro-Wilk test because this test is more appropriate for small sample sizes (less than 50 samples). The Q-Q plot is shown in Fig. 7.

A Shapiro-Wilk test indicated no significant violation of normality, $\mathrm{W}(32)=0.963, \mathrm{p}=0.324$.

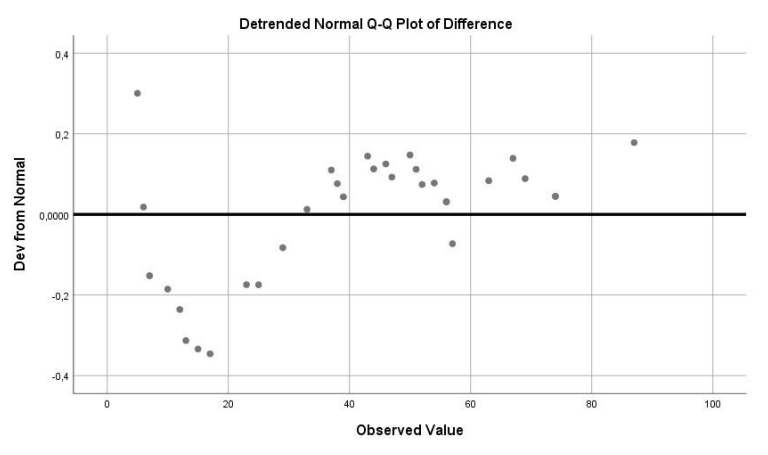

Fig. 7. Q-Q Plots of Difference on average gaze mouse path distance in pixels (source: own edited)

According to Shapiro-Wilk Tests the significance values are greater $(0.324)$ than 0.05 , so the data is normal. Also it can be seen in the Q-Q Plots, the data points are close enough to the diagonal line, not stray from the line too much, so the data is approximately normally distributed.

\section{F. Paired Samples t-test}

According to the results of previous tests it can be assessed for the differences there is no outlier and data is normal so the Paired t-test can be applied. 
Examination of the eye-hand coordination

related to computer mouse movement
A paired-sample t-test indicated that the average gaze mouse path distance was significantly higher for the computer mouse $(\mathrm{M}=407.875, \mathrm{SD}=23.46411)$ than for the gesture control $(\mathrm{M}$ $=367.2813, \mathrm{SD}=14.12898), \mathrm{t}(31)=10.166, \mathrm{p}<0.001$.

It can be seen that the means of average gaze mouse path distance at computer mouse and hand control statistically significantly different because the significance value (2-tailed) is less than 0.05. Looking at the Statistics table, it can be seen that hand control had an average gaze mouse path distance.

\section{CONCLUSIONS}

This study found that who controls the mouse pointer by traditional computer mouse has a statistically significantly greater average gaze mouse path distance $(407.9 \pm 23.46)$ compared to who use Leap Motion hand control (367.3 \pm $14.12), \mathrm{t}(22)=10.166, \mathrm{p}<0.005$. The results are probably due to the fact that computer mouse movement is a routine practice, so it requires less attention than hand motion mouse cursor control. In the case of hand motion-based mouse cursor control, the proper movement is less routine, so the path of the mouse cursor should be more closely tracked by the eyes in order to the desired controlled movement can be realized.

The results obtained with the Test environment can provide more information to identify some coordination problems, so it can provide useful information, for example, in the analysis of certain human hand activities. Based on the monitoring the process of proper handheld and visual attention, the individual coordination difficulties can be identified and corrected.

If the development of the learning environment is analyzed in terms of changes in human behavior it can be seen that a new generation is developing whose members are devotees of online education. [26-28] As a result of the influence of the above described modern, day to day changing world, higher education has tried to adapt to the new generation attitude, habits, learning style of students and started to switch over to electronic-based educational systems labeled with the term e-learning. [29-30]

The results presented in this article can be used for CogInfoCom researches which focuses of the development of approaches and methodologies for the synthesis of new human ICT capabilities based on engineering principles. [31-32]

The results obtained can assist in the development of increasingly popular 3D virtual spaces in education. Students are eager to see these new technologies because ICT is already an integral part of their culture. [33] The desktop virtual realities can serve as an effective virtual workspace which helps to expand the human cognitive capabilities. [34] VR spaces not only provide an attractive visual experience, but also the formation of new memories psychology [35], eg. ads in VR evoke better memory [36]. The results could help developing VR spaces, 3D applications which allows for better learning and has more research and testing capabilities. [37-38] VR spaces (eg. Maxwhere) allows for information to be shared and understood more quickly than when using traditionally 2D interfaces. [39-40]

However in 3D virtual space managing, accessing, and performing certain functions can be sometimes difficult and require a higher level of user routine. The results obtained can help to overcome the limitations of control to select the optimal input device (gesture-based or conventional control) for a given situation or allow the combination of the two to take advantage of their advantages to increase the effect on higher education.

\section{Acknowledgment}

The project is sponsored by EFOP-3.6.1-16-2016-00003 founds, Consolidate long-term R and D and I processes at the University of Dunaujvaros.

\section{REFERENCES}

[1] Kauffman, James M.; Hallahan, Daniel P.; Pullen, Paige Cullen. Handbook of special education. Routledge, 2017. DoI: $10.4324 / 9781315517698$

[2] Gowen, Emma; Miall, R. Chris. Eye-hand interactions in tracing and drawing tasks. Human movement science, 2006. 25.4-5: 568-585. DoI: 10.1016/j.humov.2006.06.005

[3] Mcglashan, Hannah L., et al. Improvement in children's fine motor skills following a computerized typing intervention. Human movement science, 2017, 56: 29-36. DOI: $10.1016 /$ j.humov.2017.10.013

[4] Sopa, Ioan Sabin; Pomohaci, Marcel. Study regarding the development of agility skills of students aged between 10 and 12 years old. Timisoara Physical Education and Rehabilitation Journal, 2016, 9.17: 7-16. DoI: 10.1515/tperj-2016-0009

[5] Barnett, Lisa M., et al. Fundamental movement skills: An important focus. Journal of Teaching in Physical Education, 2016, 35.3: 219-225. DoI: $10.1123 /$ jtpe.2014-0209

[6] Leo, Andrea, et al. A synergy-based hand control is encoded in human motor cortical areas. Elife, 2016. DoI: 10.7554/elife.13420.021

[7] Hand-Eye Coordination, CogniFit.com, https://www.cognifit.com/ science/cognitive-skills/eye-hand-coordination, 2019.

[8] S, Bharadwaj, B, Kumari, Electrooculography: Analysis on device control by signal processing, International Journal of Advanced Research in Computer Science, Vol. 8, No. 3, 2017.

[9] A, Gambhir, K, S, Boppaiah, M, S, Subbaiah, Pooja, M, Kiran, P, Video Oculographic System using Real-Time Video Processing, International Journal of Computer Applications (0975 - 8887), Vol. 119, No. 22, June 2015. DoI: 10.5120/21368-4400

[10] F, Weichert, D, Bachmann, B, Rudak, D, Fisseler, Analysis of the Accuracy and Robustness of the Leap Motion Controller, PubMed Central, 13(5): 6380-6393, 2013. DoI: 10.3390/s130506380

[11] L, Twardon, A, Finke, H, Ritter, Exploiting eye-hand coordination: a novel approach to remote manipulation, 2013 IEEE/RSJ International Conference on Intelligent Robots and Systems (IROS) November 3-7, Tokyo, Japan, 2013. DoI: 10.1109/IROS.2013.6697147

[12] M, Carrasco, X, Clady, Prediction of user's grasping intentions based on eye-hand coordination, The 2010 IEEE/RSJ International Conference on Intelligent Robots and Systems October 18-22, Taipei, Taiwan, 2010. DoI: 10.1109/IROS.2010.5650024

[13] I-T, Chiang, J-C, Tsai, S-T, Chen, Using Xbox 360 Kinect Games on Enhancing Visual Performance Skills on Institutionalized Older Adults with Wheelchairs, 2012 Fourth IEEE International Conference On Digital Game And Intelligent Toy Enhanced Learning, Takamatsu, Kagawa, Japan, 2012. DoI: 10.1109/digitel.2012.69

[14] V, Renata, F, Li, C-H, Lee, C-H, Chen, Investigation on the Correlation between Eye Movement and Reaction Time under Mental Fatigue Influence, 2018 International Conference on Cyberworlds, Singapore, 2018. DoI: 10.1109/cw.2018.00046

[15] M, Johns, K, Crowley, R, Chapman, A, Tucker, C, Hocking, The effect of blinks and saccadic eye movements on visual reaction times, Attention, Perception and Psychophysics, Vol. 71, No. 4, 2009, pp. 783-788. DOI: $10.3758 /$ app.71.4.783 
[16] S, Martin, A, Rangesh, E, Ohn-Bar, M, Trivedi, The Rhythms of Head, Eyes and Hands at Intersections, 2016 IEEE Intelligent Vehicles Symposium (IV) Gothenburg, Sweden, June 19-22, 2016. DOI: 10.1109/ivs.2016.7535575

[17] B, Fischer, L, Rogal, Eye-hand-coordination in man: A reaction time study, Biological Cybernetics, Vol. 55, No. 4, 11/02/ 1986, p. 253 , DoI: $10.1007 / \mathrm{bf} 00355600$

[18] H, L, Dean, D, Martí, E, Tsui, J, Rinzel, B, Pesaran, Reaction time correlations during eye-hand coordination: behavior and modeling, The Journal Of Neuroscience: The Official Journal Of The Society For Neuroscience, Vol. 31, No. 7, 2011, pp. 2399-2412, DoI: 10.1523/jneurosci.4591-10.2011

[19] Dependent T-test using SPSS Statistics, Laerd Statistics, https:// statistics.laerd.com/spss-tutorials/dependent-t-test-using-spssstatistics.php, 2019.

[20] Independent T-test using SPSS Statistics, Laerd Statistics, https:// statistics.laerd.com/spss-tutorials/independent-t-test-using-spssstatistics.php, 2019.

[21] Ooms, K., Dupont, L., Lapon, L., Popelka, S., Evaluation of the accuracy and precision of a low-cost eye tracking device, Journal of Eye Movement Research, 8(1):5, 1-24, 2015.

[22] S, Popelka, Z, Stachoň, Č, Šašinka, J, Doležalová, EyeTribe Tracker Data Accuracy Evaluation and Its Interconnection with Hypothesis Software for Cartographic Purposes, Computational Intelligence and Neuroscience, Advances in Eye Tracking Technology: Theory, Algorithms, and Applications, 2016. Dor: 10.1155/2016/9172506

[23] E, S, Dalmaijer, Is the low-cost EyeTribe eye tracker any good for research? PeerJ PrePrints 2:e585v1, 2014, p 1-35, DoI: $10.7287 /$ peerj.preprints. $585 \mathrm{v} 1$

[24] UltraLeap Leap Motion Controller Datasheet, ultraleap.com, https:// www.ultraleap.com/datasheets/Leap_Motion_Controller_Datasheet. pdf, 2019.

[25] Voßkühler, A., Nordmeier, V., Kuchinke, L., \& Jacobs, A. M. (2008) OGAMA (Open Gaze and Mouse Analyzer): open-source software designed to analyze eye and mouse movements in slideshow study designs. Behavior research methods, 40(4), 1150-1162.

[26] Molnar, Gy, Benedek, A, ICT Related Tasks and Challenges In The New Model of Technical Teacher Training, InfoWare 2013, ICCGI 2013, The Eighth International Multi-Conference on Computing in the Global Information Technology, Nice, France, 40-44, 2013.

[27] I. Heldal, C. Helgesen, The Digital HealthLab: Supporting Interdisciplinary Projects in Engineering and in Health Education, Journal of Applied Technical and Educational Sciences, Vol. 8, No. 4, pp. 4-21, 2018.

[28] R. Pinter, S. M. Cisar, Measuring Team Member Performance in Project Based Learning, Journal of Applied Technical and Educational Sciences, Vol. 8, No. 4, pp. 22-34, 2018.

[29] Molnar, Gy, The Impact of Modern ICT-based Teaching and Learning Methods in Social Media and Networked Environment, 11th International Scientific Conference on Distance Learning in Applied Informatics, Nitra, Slovakia, Wolters Kluwer, 341-350, 2016.

[30] L. Bognár, É. Fáncsikné, P. Horváth, A. Joós, B. Nagy, and G. Strauber, Improved learning environment for calculus courses, Journal of Applied Technical and Educational Sciences, Vol. 8, No. 4, pp. 35-43, 2018.

[31] P. Baranyi, A. Csapo, Gy. Sallai: Cognitive Infocommunications (CogInfoCom). Springer, 2015. DoI: 10.1007/978-3-319-19608-4

[32] P. Baranyi, Á. Csapó: Definition and synergies of cognitive infocommunications. Acta Polytechnica Hungarica, vol 9, no 1, pp. 67-83., 2012.

[33] I. Horváth: Evolution of teaching roles and tasks in VR / ARbased education, 9th IEEE International Conference on Cognitive Infocommunications, Budapest, 2018. DoI: $10.1109 /$ coginfocom.2018.8639907

[34] B. Berki: Desktop VR and the Use of Supplementary Visual Information, 9th IEEE International Conference on Cognitive Infocommunications, Budapest, 2018. DOI: $10.1109 /$ coginfocom.2018.8639925
[35] A. Csapo, L. Horvath, P. Galambos, P. Baranyi: VR as a Medium of Communication: from Memory Palaces to Comprehensive Memory Management, Proceedings of the 9th IEEE International Conference on Cognitive Infocommunications (CogInfoCom), pp. 389-394., Budapest, 2018. Dor: 10.1109/coginfocom.2018.8639896

[36] B. Berki: 2D Advertising in 3D Virtual Spaces, Acta Polytechnica Hungarica, vol 15, no 3. 2018. Dor: 10.12700/aph.15.3.2018.3.10

[37] T. Guzsvinecz, Cs. Kovacs, D. Reich, V. Szucs, C. Sik-Lanyi: Developing a virtual reality application for the improvement of depth perception, 9th IEEE International Conference on Cognitive Infocommunications, pp. 17-22. 2018. DOI: $10.1109 /$ coginfocom. 2018.8639935

[38] K. Biró, et al. The effects of virtual and augmented learning environments on the learning process in secondary school. 8th IEEE International Conference on Cognitive Infocommunications (CogInfoCom), Debrecen, Hungary, 371-376., 2017. DoI: $10.1109 /$ coginfocom.2017.8268273

[39] I. Horvath, A. Sudar: Factors contributing to the enhanced performance of the Maxwhere 3d VR platform in the distribution of digital information. Acta Polytechnica Hungarica, vol 15, no 3, 2018, pp. 149-173., DoI: 10.12700/aph.15.3.2018.3.9

[40] I. Horvath: MaxWhere 3D Capabilities Contributing to the Enhanced Efficiency of the Trello 2D Management Software. Acta Polytechnica Hungarica, vol 16, no 6, 2019, pp. 55-71. DoI: $10.12700 / \mathrm{aph} \cdot 16.6 .2019 .6 .5$

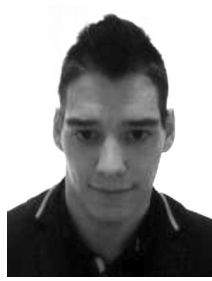

Tibor Ujbányi was born in Esztergom, Hungary in 1986. He received the BSc degree in system engineering in 2011 and MA degree in Teacher of Engineering from the University of Dunaújváros, Hungary in 2014. He is current Ph.D student in Multidisciplinary Doctoral School of Engineering of Széchenyi István University. $\mathrm{He}$ is working as a system engineer at University of Dunaújváros. His research area is Eye tracking. He has published several articles based on eye movement monitoring studies.

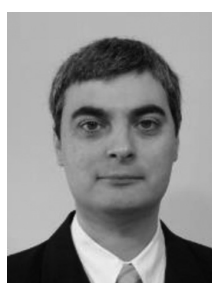

Attila Kóvári was born in Siklós, Hungary in 1975. He received the MSc degree in electrical engineering from the Budapest University of Technology and Economics, Hungary in 2001. He is associate professor, head of department and member of the Scientific Council at University of Dunaújváros. In 2014, he received a $\mathrm{PhD}$ in engineering from University of Pannonia. His main research areas: human-computer interfaces, ICT in education.

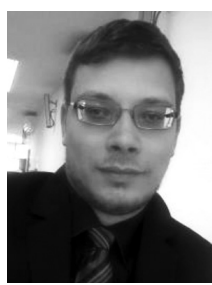

Gergely Sziládi was born in Budapest, Hungary in 1989. He received the BSc degree in system engineering in 2016 and MA degree in Teacher of Engineering from the University of Dunaújváros, Hungary in 2018. $\mathrm{He}$ is working as a system engineer at University of Dunaújváros. His research area is hand gesture control. $\mathrm{He}$ is co-author of numerous articles based hand motion control.

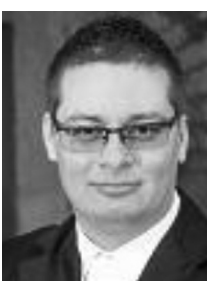

József Katona was born in Debrecen, Hungary in 1988. He received the BSc degree in software engineering in 2013 and MA degree in Teacher of Engineering from the University of Dunaújváros, Hungary in 2015. He is associate professor, head of department and member of the Scientific Council at University of Dunaújváros. In 2019, he received a PhD in informatics from Széchenyi István University. His main research areas: humancomputer interfaces, software engineering. 